
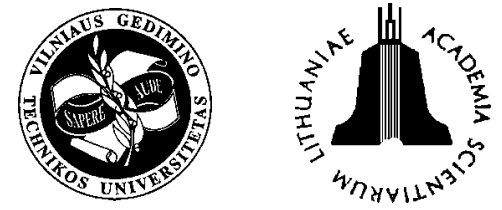

JOURNAL OF CIVIL ENGINEERING AND MANAGEMENT

http:/www.vtu.lt/english/editions

2004, Vol X, No 2, 143-150

\title{
ANALYSIS OF DIAPHRAGM BEHAVIOUR IN COMPOSITE MULTI GIRDER RAILWAY BRIDGES
}

\author{
Yannick Sieffert ${ }^{1}$, Gérard Michel ${ }^{1}$, Didier Martin $^{2}$, David Keller ${ }^{2}$ and Jean-François Jullien ${ }^{1}$ \\ ${ }^{1} U R G C$, INSA, 20 Avenue Albert Einstein, 69621 Villeurbanne Cedex, France, \\ E-mail: Yannick.Sieffert@insa-lyon.fr, Gerard.Michel@insa-lyon.fr,Jean-Francois.Jullien@insa-lyon.fr \\ ${ }^{2} S N C F$, Ingénieurs au département des Ouvrages d'Art de la direction de l'ingénierie, 122 rue des Poissonniers, \\ 75876 Paris Cedex 18, France.E-mail: didier.martin@sncf.fr, david.keller@sncf.fr
}

Received 20 Jan 2004; accepted 26 March 2004

\begin{abstract}
This study focuses on mechanical behaviour of diaphragm in composite multigirders railway bridge. The aim is to predict and to compare, with a numerical simulation, the transverse and longitudinal distribution of traffic loads in different girders and in the slab for the cases with and without intermediary diaphragm. A 3-D finite element model is developed to represent the actual geometry of multigirder bridge. Durability of the concrete bridge deck is directly related to cracking, so a non-linear constitutive equation is used for the concrete deck. This study focuses on the response of a bridge with and without dipahragm under a UIC and TGV loading. To achieve this aim, a static failure analysis is performed. Our analysis concluded that diaphragm is not necessary, so it seems to be possible to remove the diaphragms.
\end{abstract}

Keywords: concrete, steel, bridge, composite, multigirder, diaphragm, speed train.

\section{Introduction}

Multigirder steel bridges are common throughout the world. In France, composite multigirder bridges are frequently used for road traffic but also for the railway traffic. The girders span is in the direction of traffic and serve as the primary load carrying members. The concrete armed slab is connected to the girders and increase the stiffness of the bridge. The thickness of this slab and the height of the girders for railway bridges can be twice as high as for roadway bridges. Indeed, the stability of the rail/wheel contact requires a very significant structure stiffness and a very small deflection. In order to transmit the loading of the slab to the whole girders, transverse steel members, or diaphragms connecting them together is used. Moreover, the diaphragm preventing resistance in case of accidental lateral loading. Diaphragms also stabilise the girders during construction and placement of the deck. However, the real contribution of the diaphragms on the bridges is not well-known. A diaphragm is composed of several sections of girders transversally connecting the principal beams between them. Its non-continuity leads to its bad mechanical comportment regarding the transverse stiffness. Kosterm and deCastro [1] estimated that only 25 to $35 \%$ of diaphragm's moment of inertia participated in the lateral distribution of the live load.
The review of available literature indicates clearly that the contribution of diaphragm is not really know. The recommendations of various authors are contradictory to one another. For example, Stevens and Gosbell [2] conclude that intermediate diaphragms do not significantly affect live load distribution. Culham and Ghali [3] find intermediate diaphragms do affect transverse distribution of live load. This contradiction comes to the fact that each studies were carried out on arbitrarily chosen bridges. Moreover, the manner of modelling the behaviour of the bridge is different. The composite multigirders bridge behaviour were very studied in the sixties and seventies. At that time, the computation possibilities did not authorise to deal with this problem in geometry space representation. This way, the behaviour of bridge with girders and diaphragms was idealised as a gird of beams [4]. The elements used were two nodes beam elements. Today with actual numerical capability, this type of modelling is very simple. However, the qualification of the diaphragm impact on this type of bridge requires an analysis in three dimensions. The powerful computers enable us to represent bridges using 3D elements. Chen in 1995 [5] modelled I-shape girders and diaphragm with beams elements and the slab with shell elements. The composite action between slab and girder is effected by connecting the centre of gravity of slab and girder with rigid link elements. Tedesco et al in 1995 [6] used 
shell elements for flanges, webs and for the slab. They did not use shell elements for diaphragms but beam elements with rigid links because their mesh did not enable them to correctly associate the position of the diaphragm with web elements in their mesh representation. This requires a very fine mesh with a great number of elements in order to enable the right representation of the various assemblies of the parts.

Usually, we do not want to unnecessarily weigh down the models, only the significant zones (like assembly of parts of various size, zones of strong constraints) are meshed finely. The remainder of the structure - not being the place of significant phenomenon development is meshed more coarsely. But, in case of a bridge, this method is not possible. Furthermore, dynamic analysis of bridges requires a loading moving on the slab $[7,8]$. To ensure pertinence of the results, the size of the elements must be the same on all the surface of displacement of the loading. The size of the element in the assemblies (diaphragm/girder) determines those of the whole structure.

\section{Meshing of the bridge}

The FEM analyses were conducted on a Unix station through implementation of the Abaqus version 6.3 [9] finite element computer programs.

In order to investigate the contribution of the intermediate diaphragm in composite multigirder bridges, we choose to model an existing SNCF bridge at BONPAS, on the new high-speed line connecting Lyon to Marseille which has more than 500 civil engineering works. This bridge was selected in this study for its simplicity. It's a simply supported span of $30 \mathrm{~m}$ with no skew and which carries 2 traffic lanes. There are four 1,7 $\mathrm{m}$ deep steel girders spaced transversely at $3,2 \mathrm{~m}$, and a $0,4 \mathrm{~m}$ thick reinforced concrete deck slab with acts compositely with the steel girders (Figs 1, 2).

As the thickness of beam flange or web is very small (a few centimetres) in regard with the length (several tens of meters) and the width of the beam (about one meter), the shell theory is relevant.

The girder flanges are essentially in a state of plane stress. Therefore, the flanges were modelled with the fournode shell element with 5 DOF per node (S4). In order

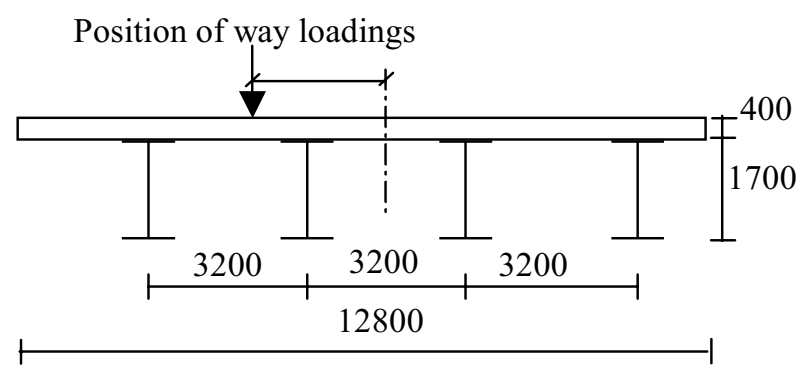

Fig 1. Cross-section of the bridge systems

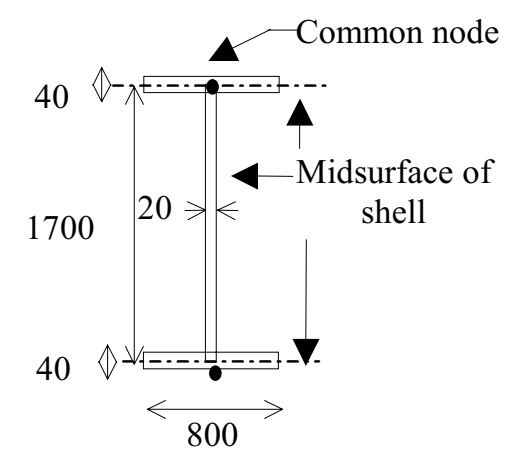

Fig 2. Girder detail

to model accurately the out-of-plane flexure of the girder webs caused by the diaphragms, the webs were also modelled with the four-node shell element. In this manner, the in-plane stress and the slight torsional and flexural stiffness of the flanges could be accounted by the model. In order to obtain an identical stiffness between the girders flanges and those of the diaphragms, 4 elements are used in the width of the flanges and the diaphragms (Fig 3).

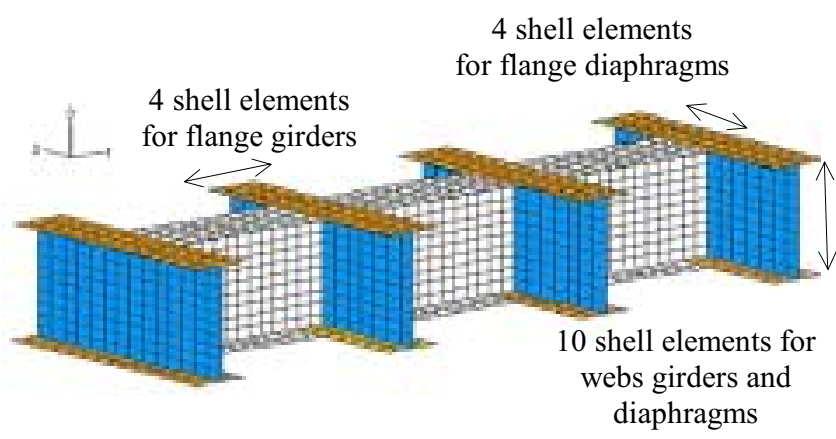

Fig 3. Diaphragm-to-girder connection detail

The discritisation of the concrete slab of a mixed structure requires a particular attention. Tedesco et al [6] use also shell elements for the slab because its thickness is not very important. In the case of high-speed train bridge, the thickness of the slab deck requires an approach with volume element in order to consider the stress in the thickness (Fig 4). We used volume elements with eight nodes (C3D8). Moreover, to describe correctly the behaviour of the concrete slab we take into account the presence of the reinforcement. We use four volumes layers of elements in order to position the reinforcement, with 2 nodes elements bars (B31) in the first and second layer (Fig 5).

\section{Materials model - non-linear constitutive equation}

Today, the modelling of concrete behaviour is still a significant numerical problem due to its very strong non-linearity and the presence of negative hardening in tension. Historically, some composite multigirder bridges 


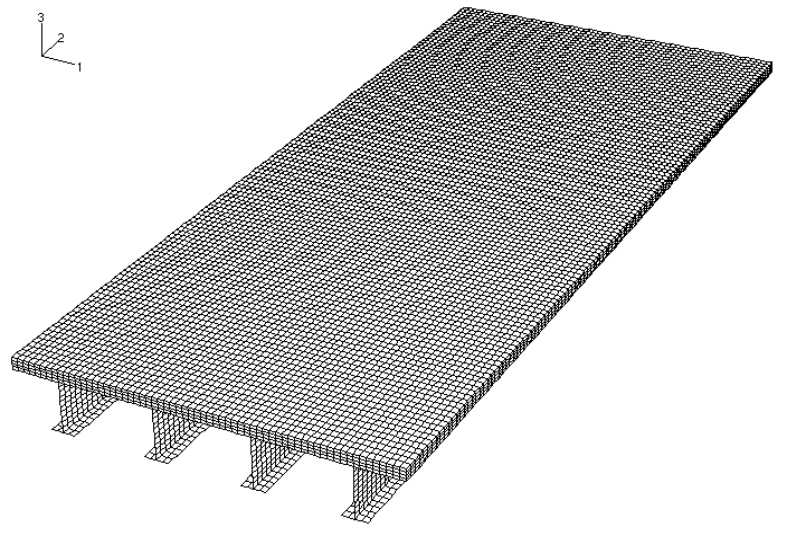

Fig 4. Isometric view of FEM model

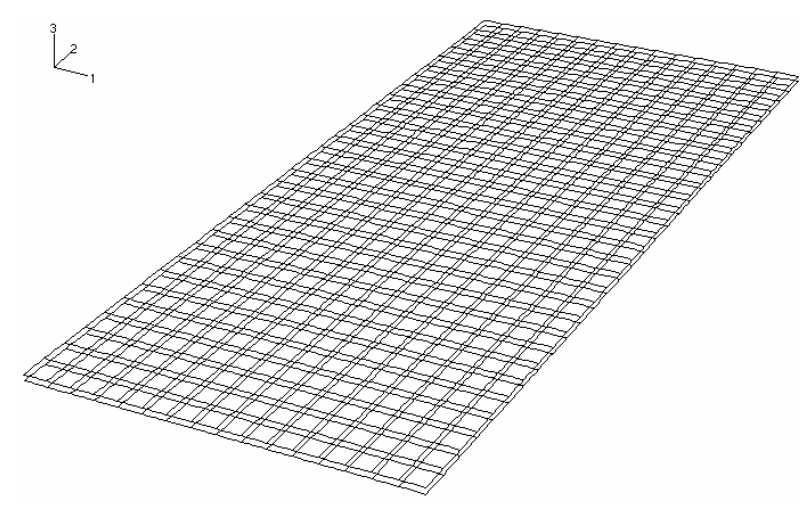

Fig 5. Reinforcement elements in slab

study consider the concrete as perfectly elastic $[2,10]$. More recently, the concrete slab in composite multigirder is regarded as always compressed with a constitutive plasticity equation $[5,11]$ or then the cracking of the slab is taken into account before the analysis thanks to an orthotropic description of the concrete [6]. Without diaphragm, the transverse flexion of the deck is significant and the concrete slab between two constitutive beams is then subjected to tensile stresses. It is thus significant to use concrete damaged plasticity material model which assumes that the main two failure mechanisms are tensile cracking and compressive crushing. The concrete damaged plasticity model developed by Lubliner et al [12] and completed by Lee and Fenves [13] is used in the programs based on the finite element method ABAQUS version 6.3. The model uses concepts of isotropic damaged elasticity in combination with isotropic tensile and compressive plasticity to represent the inelastic behaviour of concrete. The model assumes non-associated potential plastic flow. The evolution of the yield surface is controlled by two hardening variables, $\widetilde{\varepsilon}_{t}^{p l}$ and $\widetilde{\varepsilon}_{c}^{p l}$, linked to failure mechanisms under tension and compression loading, respectively. In terms of effective stresses, the yield function takes the form:

$$
\begin{array}{r}
f=\frac{1}{1-\alpha}\left(\bar{q}-3 \alpha \bar{p}+\beta\left(\widetilde{\boldsymbol{\varepsilon}}^{\mathbf{p l}}\right)\left\langle\hat{\bar{\sigma}}_{\max }\right\rangle-\gamma\left(-\hat{\bar{\sigma}}_{\max }\right\rangle\right) \\
-\overline{\boldsymbol{\sigma}}_{c}\left(\widetilde{\varepsilon}_{c}^{p l}\right)=0
\end{array}
$$

with

$$
\begin{gathered}
\alpha=\frac{\left(\sigma_{b 0} / \sigma_{c 0}\right)-1}{2\left(\sigma_{b 0} / \sigma_{c 0}\right)-1} ; \quad 0 \leq \alpha \leq 0,5, \\
\beta=\frac{\bar{\sigma}_{c}\left(\widetilde{\varepsilon}_{c}^{p l}\right)}{\bar{\sigma}_{t}\left(\widetilde{\varepsilon}_{t}^{p l}\right)}(1-\alpha)-(1+\alpha), \\
\gamma=\frac{3\left(1-K_{c}\right)}{2 K_{c}-1},
\end{gathered}
$$

$\langle x\rangle=(x+x) / 2$ denotes the Macaulay bracket function. Here

$\bar{p}=-\frac{1}{3} \operatorname{trace}(\overline{\boldsymbol{\sigma}})$ is the first invariant of the effective stress tensor, namely the hydrostatic pressure stress,

$\bar{q}=\sqrt{\frac{3}{2}(\mathbf{S}: \mathbf{S})}$ is the second invariant of the effective stress tensor, namely the Mises' equivalent effective stress where $\overline{\mathbf{S}}$ is the effective stress deviator: $\overline{\mathbf{S}}=\overline{\boldsymbol{\sigma}}+\bar{p} \mathbf{I}$,

$\hat{\bar{\sigma}}_{\max }$ is the maximum principal effective stress,

$\sigma_{b 0} / \sigma_{c 0}$ is the ratio of initial equibiaxial compressive yield stress to initial uniaxial compressive yield stress (we used the default value 1,16 ),

$K_{c}$ is the ratio of the second stress invariant on the tensile meridian to that on the compressive meridian at initial yield for any given value of the pressure invariant such that the maximum principal stress is negative, $\hat{\bar{\sigma}}_{\max }<0$ (we used the default value $2 / 3$ ),

$\bar{\sigma}_{t}\left(\widetilde{\varepsilon}_{t}^{p l}\right)$ is the effective tensile cohesion stress and $\bar{\sigma}_{c}\left(\widetilde{\varepsilon}_{c}^{p l}\right)$ is the effective compressive cohesion stress.

The model assumes that the uniaxial tensile and compressive response of concrete is characterised by damaged plasticity, as shown in Figs 6 and 7.

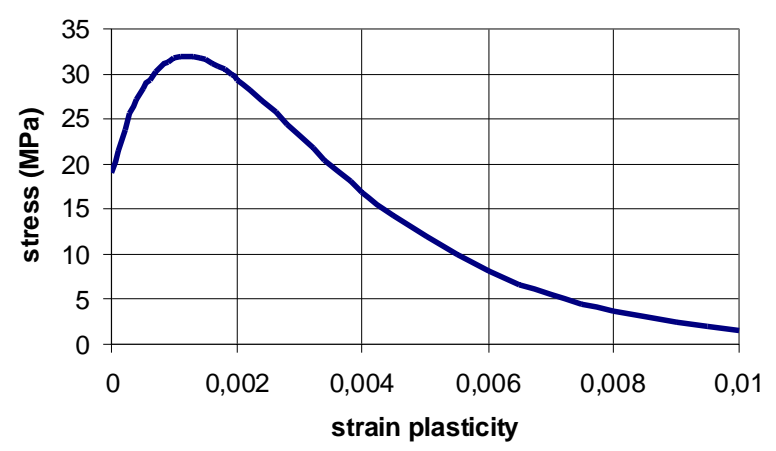

Fig 6. Compressive concrete model 


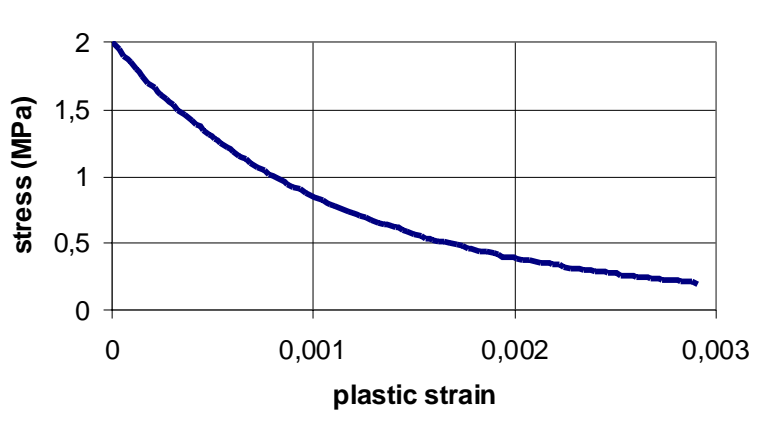

Fig 7. Tensile concrete model

The following material properties of concrete are used in this study: the Young's modulus: $E_{0}=35000$ $\mathrm{MPa}$, the maximum tensile strength $f_{t}^{\prime}=2 \mathrm{MPa}$, the fracture energy in the uniaxial tensile state $G_{t}=0,06 \mathrm{~N} / \mathrm{mm}$, the maximum compressive strength $f_{c}^{\prime}=32 \mathrm{MPa}$ and the fracture energy in the uniaxial compressive state $G_{c}=$ $6 \mathrm{~N} / \mathrm{mm}$.

The behaviour of steel is regarded as perfectly plastic with a limit of elasticity to $355 \mathrm{MPa}$ and a Young's modulus $E_{0}=210000 \mathrm{MPa}$. The plastic work of the girders is not authorised to ensure the continuation of the bridge.

\section{Trains loads}

Eurocodes 1 [14] defines a train loads called UIC 71 for the rails bridges dimensioning (Fig 8). This loading is 8 times more significant than TGV. Its use makes it possible to obtain a very significant safety for the static analyse of the bridge.

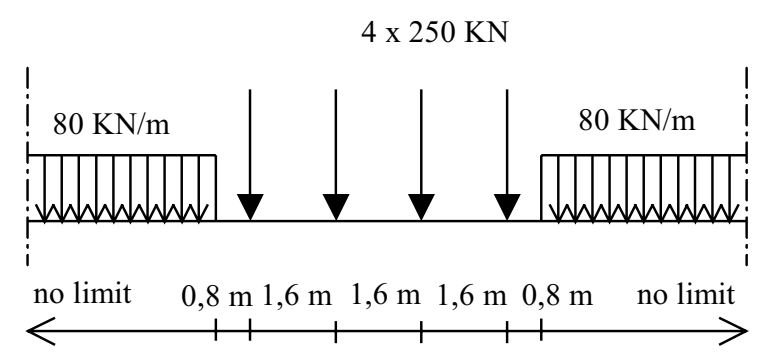

Fig 8. UIC loading

However, the dynamic analysis requires to use a real TGV loading. This latter is composed of 15 bogies and 30 axles of $170 \mathrm{KN}$. Each bogie is spaced of $18,7 \mathrm{~m}$ and the distance between two axles of the same bogie (two wheel assembly) is $3 \mathrm{~m}$ (Fig 9).

The ballast thickness is equal to $0,6 \mathrm{~m}$ and distributes the loads (UIC or TGV) on a transverse distance from $2,8 \mathrm{~m}$. In the longitudinal direction of the structure, the impact of the wheels is distributing on 3 sleepers. Thus, structural consideration bridges make it possible to transcribe the solicitations since distributed loading (Fig 10).

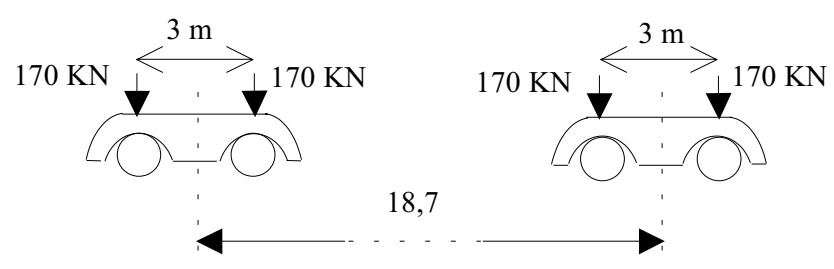

Fig 9. Two bogies of TGV

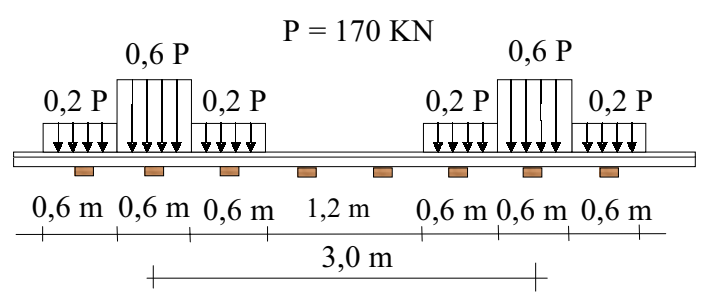

Fig 10. Distributed loading of a bogie

\section{Static analyses}

\subsection{Self-weight}

The self-weight of the structure is very significant. It is composed of the self-weight of the beams, the concrete slab and the ballast, which corresponds to a load of $305 \mathrm{KN} / \mathrm{ml}$. Under a solicitation of self-weight, the bridge deflection is under pure longitudinal bending. The mixed structure is then very powerful because the concrete is completely compressed and the vertical deflection is about $3 \mathrm{~cm}$. With or without diaphragm, there is no significant change in terms of deflection and stress (Figs 11, 12).

\subsection{UIC loading}

Under an UIC loading and self-weight of the structure, the concrete is subjected to bottom face tensile stresses, these stresses occur only in the case without diaphragm. They are very small in the longitudinal direction (Fig 13) but they reach $\mathrm{ftj}$ in the transverse direction (Fig 14). They are located in the section of the slab located between two girders, under the loading. The diaphragm enables to associate the composite concrete and steel behaviour in the transverse direction and thus to make the slab in compression. Without diaphragms, only the concrete takes the transverse bending moments, which leads to the appearance of lower face cracks and more significant compression stresses on the upper face. A non-linear model in compression and traction for the concrete is thus necessary for analysing the influence of the diaphragm on a composite multigirder.

There is no significant difference with or without diaphragm in the vertical deflection slab at midspan (Fig 15). The behaviour of the concrete slab is linear with the diaphragm, which corresponds to the assump- 


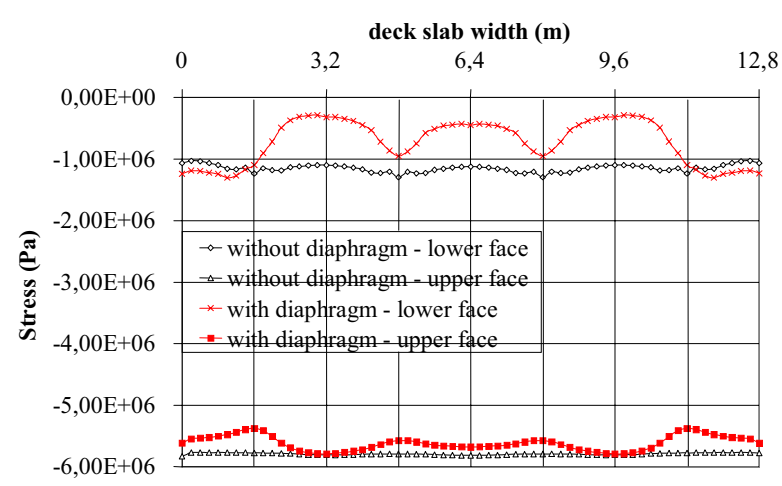

Fig 11. Longitudinal stress in slab at midspan

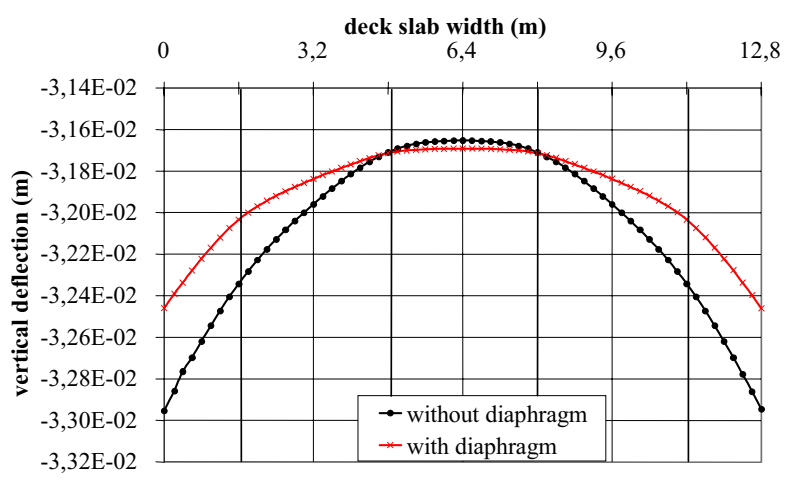

Fig 12. Vertical deflection in slab at midspan

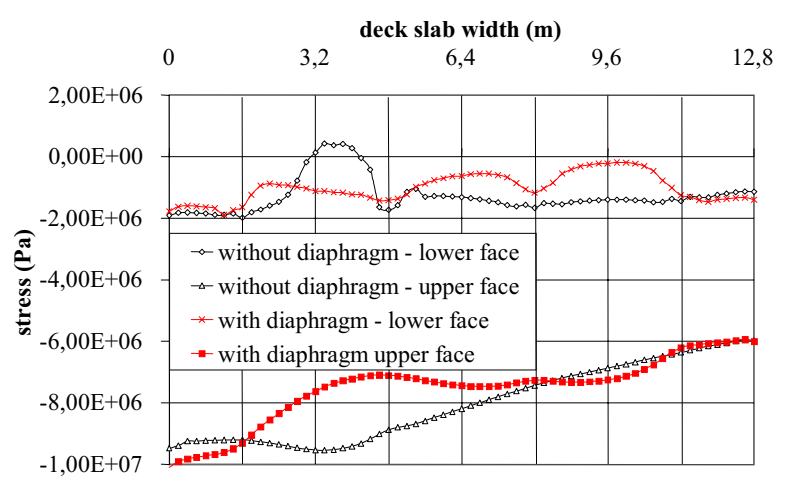

Fig 13. Longitudinal stress in slab at midspan

tion of an infinitely rigid diaphragm according to Courbon. Courbon's theory [15] gives a transverse distribution of UIC loading on the 4 girders such as 19/40P, 13/40P, 7/40P and 1/40P. This simple method makes a very good prediction. Without diaphragm the slab is less rigid and a small inflection occurs.

\subsection{TGV loading}

The real TGV loading is lower than UIC. This is why, the stress and the vertical deflection are less significant. With or without diaphragm, the longitudinal

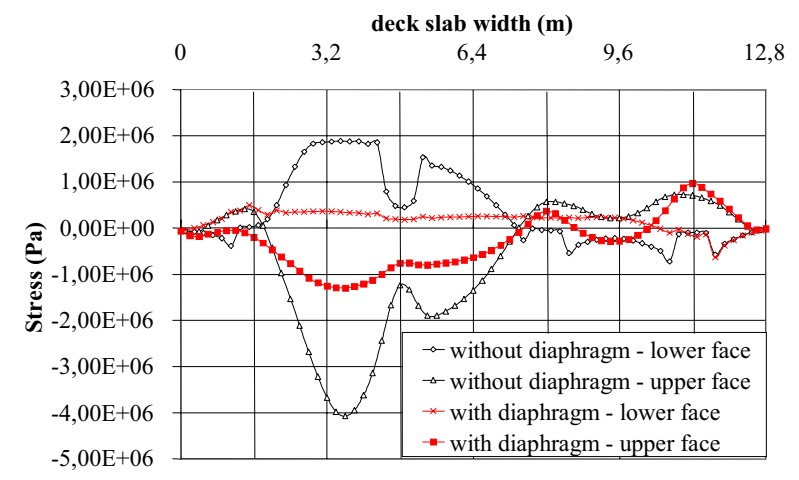

Fig 14. Turansversal stress in slab at midspan

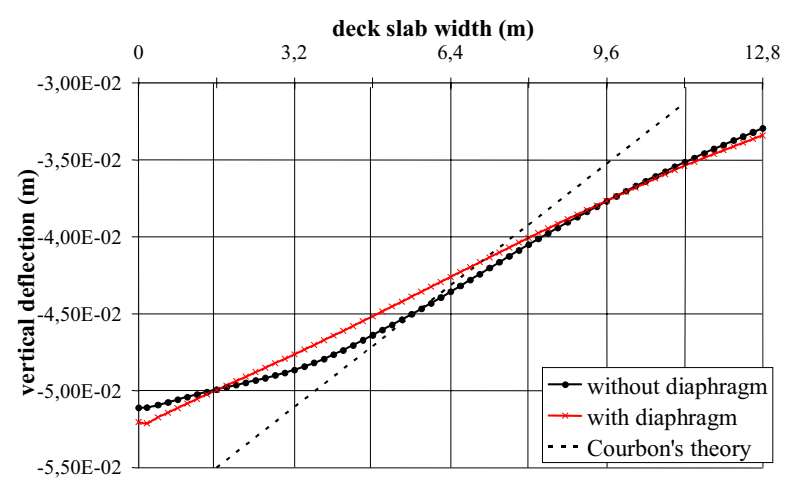

Fig 15. Vertical deflection in slab at midspan

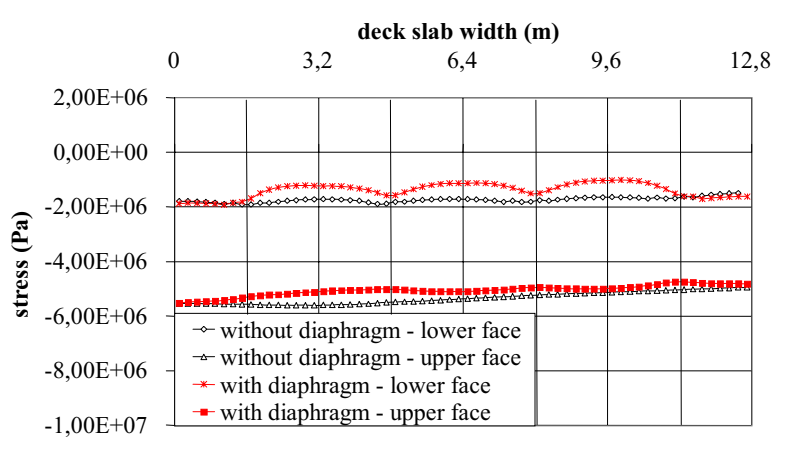

Fig 16. Longitudinal stress in slab at midspan

stress (Fig 16) and the vertical deflection (Fig 17) are identical. The contribution of the diaphragm over the transverse bending moment is not important. The transverse stress are twice lower than $\mathrm{ftj}$ (Fig 18). So the use of a sophisticated concrete damaged plasticity material model is not necessary any more because the concrete remains in the elastic range.

The vertical deflection created by the TGV is about $3 \mathrm{~mm}$, whereas thus created by the self-weight is ten more significant. This is why, the influence of the dissymmetrical loading of the TGV is finally negligible. With or without diaphragm, the response of the bridge is in adequately with Courbon's theory (Fig 17). 


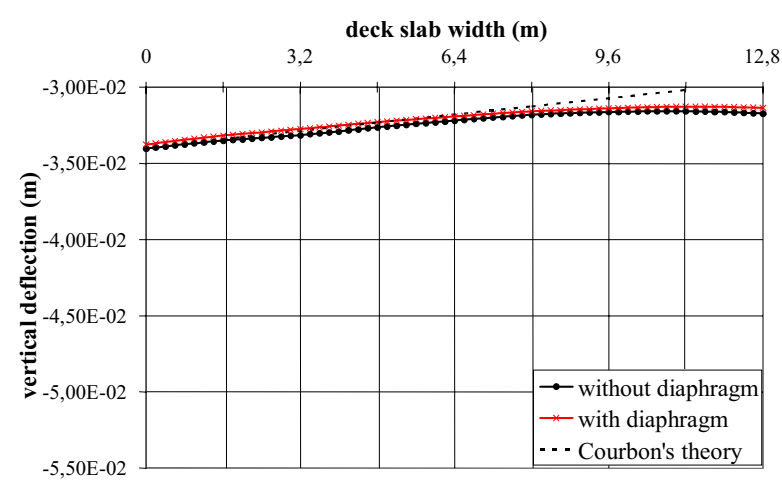

Fig 17. Vertical deflection in slab at midspan

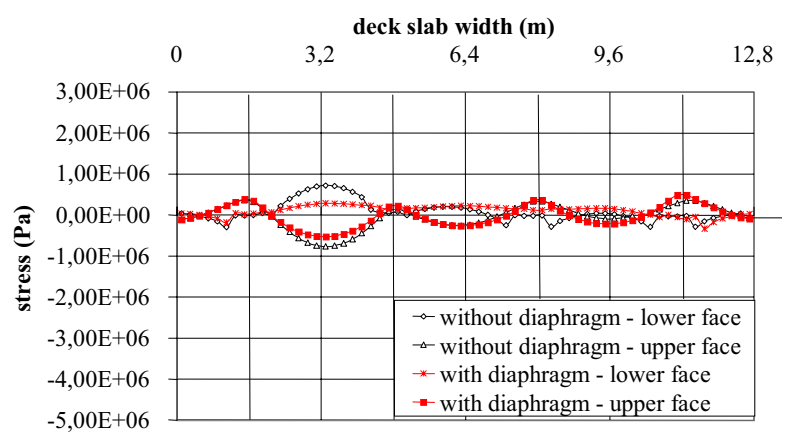

Fig 18. Transversal stress in slab at midspan

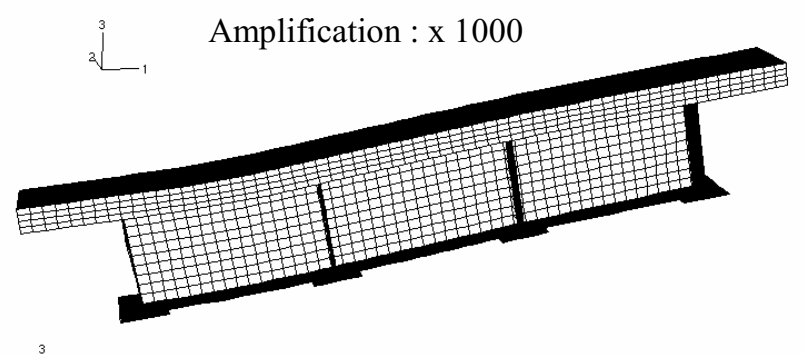

Fig 19. Deformed shape at midspan with diaphragm

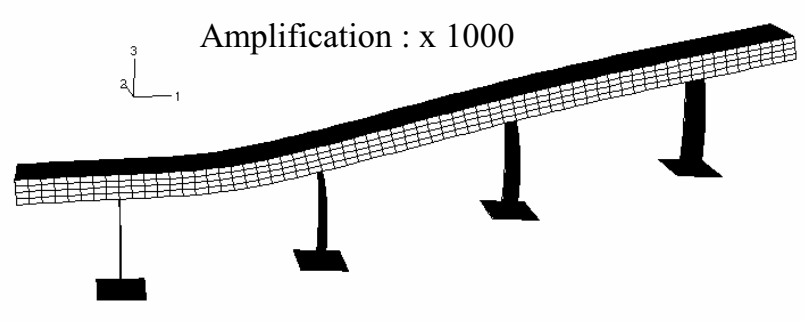

Fig 20. Deformed shape at midspan without diaphragm
The diaphragm preserves the orthogonality of the flanges and the webs girders sections (Fig 19). Without diaphragm, the girders webs were subject to a rotation (Fig 20) but it is very small (the horizontal deflection is 10 times smaller than the vertical deflection). However, although no risk of swaying of the beams is noted for a TGV loading, it can be interesting to limit webs rotations for loadings more significant. With this intention, the replacement of diaphragm by simple web stiffener makes it possible to maintain the orthogonality of the sections.

The static analysis enables us to conclude that under a TGV loading, the diaphragm can be removed. However, it would be preferable to know precisely the type of convoy which must cross the bridge. Indeed, without diaphragm, tension cracks in the slab deck occur under heavy railway traffic, which can involve a risk of corrosion of the reinforcement, and may decrease the long-term performance of the slab.

\section{Failure analysis}

For a better understanding of the contribution of the intermediate diaphragm on the structural behaviour, we studied its response up to the failure. We used "modified Riks method" to perform the collapse. This method is useful for solving ill-conditioned problems such as limit load problems [16]. We have increased the load corresponding to the TGV in order to determine the ultimate load. Fig 21 (a-h) shows the cracking pattern of the bottom surface of the FEM model at different load level. Without diaphragm, the microcraking started to appear in the slab with a load equivalent to $3 \mathrm{TGV}$ in the longitudinal direction (Fig 21a) and the rupture happened with a load equivalent to $19 \mathrm{TGV}$ (Fig 21d). The rupture is situated in the concrete armed slab in the middle span. This rupture happens when the transverse slab reinforcements below the slab cannot resist any more. With the diaphragm, the cross-section of the bridge works like a composite beam and the beginning of microcraking in the slab is obtained for $6 \mathrm{TGV}$ in the longitudinal direction (Fig 21e). Tensile stresses are in the diaphragm and the concrete remains compressed. Thus the rupture is not located in the slab but in the bearing girders. The stresses in the girders attain the plastic limit in the longitudinal direction for $19 \mathrm{TGV}$ equivalent load (Fig 21h).

The normal loading uses the bridge at only $5 \%$ of its ultimate resistance. This is why the influence of the intermediate diaphragm is not significant.

The static analysis enables us to conclude that under a TGV loading, the diaphragm can be removed. However, it would be preferable to know precisely the type of convoy that is likely to the bridge. Indeed, without diaphragm, tension cracks in the slab deck occur under heavy railway traffic. This can involve a risk of corrosion of the reinforcement, and may decrease the long-term performance of the slab. 


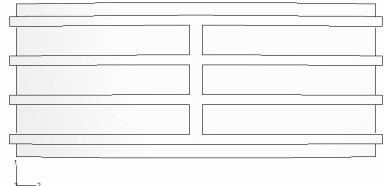

(a)
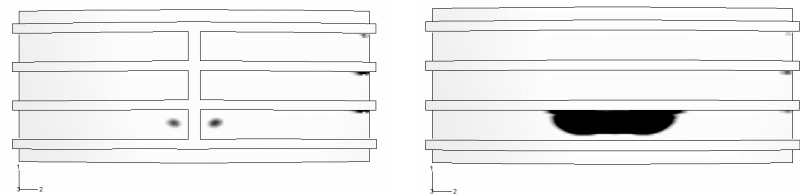

(b)

Load equivalent at $6 \mathrm{TGV}$

(f)
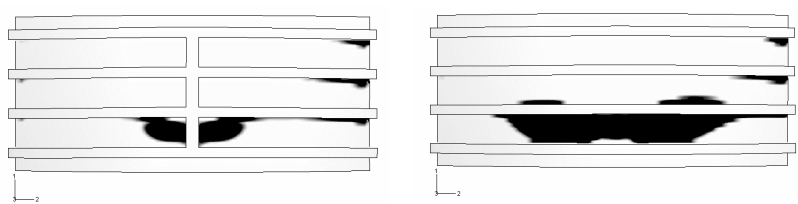

(c)

Load equivalent at $10 \mathrm{TGV}$

(g)
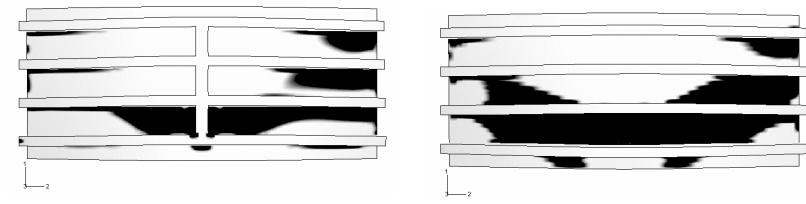

(d)

Load equivalent at $19 \mathrm{TGV}$

(h)

Fig 21. Craking pattern of bottom surface: with diaphragm (a-d) and without diaphragm (e-h)

\section{Modal analysis}

The modal analysis enables us to know the natural frequencies of the system. In addition, the analysis gives the critical speeds of TGV at which the resonance vibration may occur. They are due to two reasons: repeated action of axle loads and high speed itself [8]. As the record speed of the TGV in France is about $500 \mathrm{~km} / \mathrm{h}$, we only study the natural frequency giving critical speeds below this limit.

With a diaphragm, the number of acceptable natural frequency is 2, whereas without diaphragm, it is 6 (Table 1 and Fig 22). The absence of diaphragm increases the risk of resonance. The supplementary four modes correspond to the same frequency and they represent girders excitation. It is impossible to conclude without analysing the dynamic behaviour of the bridge in order to know the influence of the diaphragm on these natural frequencies and in particular for the four modes corresponding to vibrations beams. This will be the subject of a future work.

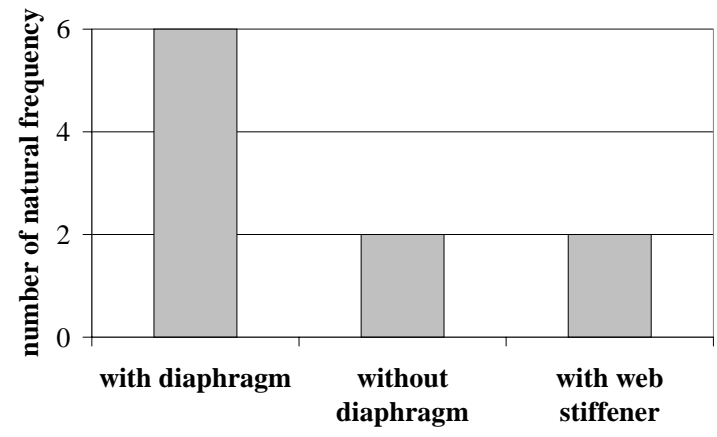

Fig 22. Number of natural frequency

Table 1. Value of natural frequency

\begin{tabular}{c|c|c|c|c|c|c}
\hline & \multicolumn{2}{|c|}{$\begin{array}{c}\text { With } \\
\text { diaphragm }\end{array}$} & \multicolumn{2}{c|}{$\begin{array}{c}\text { Without } \\
\text { diaphragm }\end{array}$} & \multicolumn{2}{c}{ With web stiffener } \\
\hline Mode & $\begin{array}{c}\text { Freq. } \\
(\mathrm{Hz})\end{array}$ & $\begin{array}{c}\text { Critica } \\
\text { speeds } \\
(\mathrm{km} / \mathrm{h})\end{array}$ & $\begin{array}{c}\text { Freq. } \\
(\mathrm{Hz})\end{array}$ & $\begin{array}{c}\text { Critical } \\
\text { speeds } \\
(\mathrm{km} / \mathrm{h})\end{array}$ & $\begin{array}{c}\text { Freq. } \\
(\mathrm{Hz})\end{array}$ & $\begin{array}{c}\text { Critical } \\
\text { speeds } \\
(\mathrm{km} / \mathrm{h})\end{array}$ \\
\hline 1 & 3,10 & 209 & 3,10 & 209 & 3,12 & 210 \\
\hline 2 & 4,41 & 297 & 4,32 & 291 & 4,42 & 298 \\
\hline 3 & & & 4,42 & 297 & & \\
\hline 4 & & & 4,46 & 300 & & \\
\hline 5 & & & 4,51 & 304 & & \\
\hline 6 & & & 4,59 & 309 & & \\
\hline
\end{tabular}

\section{Conclusions}

This study shows that, with and without intermediate diaphragm, the deflection and the stress in steel and concrete are not very different under static TGV load. However, without diaphragm, the tensile stress inside the slab is more important for heavy trains and some cracks appear. Without diaphragm, some additional modes appear and correspond to an excitation of beams only. So they probably do not influence the deflection of slab deck under the TGV and thus the good dynamic behaviour of the bridge.

\section{Acknowledgements}

The research reported herein has been sponsored by France national project MIKTI and SNCF.

\section{References}

1. Kosterm, C. and deCastro, E. Effects of diaphragms on lateral load distribution in beam-slab bridges. Transport Research Board, No 645, 1979, p. 6-9.

2. Stevens, L. K. and Gosbell, K. B. Model analysis of composite beam and slab bridge, Proceedings, Australian Road Research Board, Vol 2, Part 2, 1964, p. 1326-1343.

3. Culham, G. A.; Ghali, A. Distribution of wheel loads on bridge girders. Canadian Journal of Civil Engineering, Vol 4, 1977, p. 57-65. 
4. Cheung, M. S.; Jategaonkar, R. and Jaeger, L. G. Effects of intermediate diaphragms in distributing live loads in beam-and-slab bridges. Canadian Journal of Civil Engineering, Vol 13, 1986, p. 278-292.

5. Chen, Y. Prediction of lateral distribution of vehicular live loads on bridges with unequally spaced girders. Computers \& Structures, Vol 54, No 4, 1995, p. 609-620.

6. Tedesco, J. W.; Stallings, J. M. and Tow, D. R. Finite element method analysis of bridge girder-diaphragm interaction. Computers \& Structures, Vol 56, No 2/3, 1995, p. 461-473.

7. Au, F. T. K.; Cheung, Y. S. and Cheung, Y. K.; Vibration analysis of bridges under moving vehicles and trains: an overview. Prog. Struct. Engng Mater., Vol 3, 2001, p. 299 304.

8. Fr ba, L. A rough assessment of railway bridges for highspeed trains. Engineering Structures, Vol 23, 2001, p. 548556.

9. Abaqus documentation, version 6.3, Hibbit, Karlsson \& Sorensen, Inc., 2002.

10. Yoo, C. H. and Littrell, P. C. Cross-bracing effects in curved stringer bridges. Journal of structural engineering, Vol 112, No 9, sep. 1986, p. 2127-2140.
11. Wang, T. L.; Huang, D.; Shahawy, M. and Huang, K. Dynamic response of highway girder bridges, Computers \& Structures, Vol 60, No 6, 1996, p. 1021-1027.

12. Lubliner, J.; Oliver, J.; Oller, S. and Oñate, E. A plasticdamage model for conrete. Int. J. Solids Structure, Vol 25, No 3, 1989, p. 299-326.

13. Lee, J. and Fenves, G. Plastic-damage model for cyclic loading of conrete structures. Journal of engineering mechanics, Vol 124, No 8, 1998, p. 892-900.

14. EUROCODES 1, Actions on structures, part 3, traffic loads on the bridges, ENV 1991-3, Oct 1997.

15. Courbon, J. Calculation of multigirder bridges with diaphragms (calcul des ponts à poutre multiples solidarisées par des entretoises). Annales des ponts et chaussées de France, mémoires et documents relatifs à l'art des constructions et au service de l'ingénieur, No 17, 1940, p. 293 322 (in French).

16. Crisfield, M. A. A fast incremental/iteration solution procedure that handles 'Snap-Through'. Computers \& structures, Vol 13, No 1-3, 1981, p. 55-62. 